\title{
A Numerical Study of Turbulent Processes in the Marine Upper Layers
}

\author{
Patrice Klein ${ }^{1,2,3}$ and Michel Coantic ${ }^{1}$ \\ (Manuscript received 14 July 1980 , in final form 26 January 1981)
}

\begin{abstract}
A second-order turbulence closure model, similar to Mellor and Yamada's (1974) level-3 model, is implemented. This is used to investigate the role of the different turbulent processes and the resulting dynamical and thermal structures, for oceanic upper layers subjected to a variety of unsteady atmospheric forcings. From the distributions obtained for current and temperature, turbulence levels, the production, transfer and dissipation terms in the turbulent kinetic energy and temperature variance budgets, the physics of the oceanic mixed layer and thermocline can be discussed and comparisons made with the models of Mellor and Durbin (1975), Warn-Varnas and Piacsek (1979) and Kundu (1980) and some experimental data. Most often, shear production and viscous dissipation of turbulent kinetic energy dominate within the mixed layer. Gravitational production or destruction and turbulent diffusion, however, play a crucial role in thermocline evolution. Under strong winds, current shear and turbulence diffusion at the base of the mixed zone control the erosion mechanism, while the effect of surface wave breaking seems rather limited. After a significant wind-speed reduction, turbulence regresses upward, leaving behind quasi-free inertial current oscillations. Surface cooling enhanced turbulence and mixing, whereas solar heating results in a diminished turbulent zone and a diurnal secondary thermocline. The time variability of atmospheric forcings appears as a determinant factor for the oceanic mixed layer.
\end{abstract}

\section{Introduction}

The actual understanding of the effects of atmospheric forcings on the dynamical and thermal structure of the marine mixed layer and thermocline necessitates a proper knowledge of the mechanisms and influences of the different turbulent transfer processes involved (see, e.g., Zilitinkevich et al., 1979). Likewise, the study of the marine upper layer ecosystems requires an adequate description of vertical turbulent mixing (Jamart et al., 1977).

The relevant experimental information still appears as quite unsatisfactory because of the difficult measurement conditions, so that only orders of magnitude of certain turbulent mechanisms in a few particular situations are known (for reviews see Nihoul, 1980; Woods, 1981). An alternative involves recourse to modern turbulence modeling techniques, which have been shown to provide useful information concerning the turbulent dynamical and thermal processes in cases when measurements are not available. As is well known, the essence of these techniques is to complement the sets of partial differential equations for the first, second and eventually third-order moments of turbulent fluctuations with appropriate closure assumptions guided and calibrated after the-

\footnotetext{
${ }^{1}$ Institut de Mécanique Statistique. de la Turbulence, Laboratoire Associé au C.N.R.S, 13003 Marseille, France.

${ }^{2}$ Département E.A.A., Direction des Etudes et Recherches d'Electricité de France, 78400 Chatou, France.

${ }^{3}$ Present affiliation: Station Zoologique, B.P. 28, 06230 Villefranche sur mer, France.
}

oretical considerations and laboratory data (Lumley and Khajeh-Nouri, 1974).

Turbulence models with different levels of complexity are currently utilized; the most frequently used second-order models are known to simulate turbulent processes quite realistically in most cases, except certain extreme situations. Considering anisotropy as a small perturbation, more and more simplified models can be developed (Mellor and Yamada, 1974). Third-order models, and even more or less simplified second-order models, have been successfully applied to the atmospheric boundary-layer simulation (Donaldson, 1973; Wyngaard and Cote, 1974; Yamada and Mellor, 1975; Zeman and Lumley, 1976; Andre et al., 1976; 1978). A degenerated model (involving a variable turbulent exchange coefficient) has been used for the marine mixed layer and thermocline simulation has been used by Mellor and Durbin (1975), while Warn-Varnas and Piacsek (1979) and Kundu (1980) have more recently utilized third- and second-order turbulence models.

The present study makes use of a Simplified Second-Order Model (SSOM) close to the level 3 model in Mellor and Yamada (1974) to simulate marine upper layers subjected to dynamical and thermodynamical atmospheric forcing. The physical implications of this model are first discussed, then attention is focused on the evolutions of the different turbulent mechanisms, and their roles in thermocline deepening. The model results are also compared with some field and laboratory data, and with the description given by the other models mentioned above. 
2. Summary and discussion of the simplified secondorder model

\section{a. Equations and notations}

The present model is one-dimensional and neglects salinity effects. The closure and simplifying assumptions made are given in the Appendix. The model equations are

$$
\begin{aligned}
& \frac{\partial \bar{U}}{\partial t}=-\frac{\partial}{\partial z}\left(\overline{u^{\prime} w^{\prime}}-\nu \frac{\partial \bar{U}}{\partial z}\right)+f \bar{V}, \\
& \frac{\partial \bar{V}}{\partial t}=-\frac{\partial}{\partial z}\left(\overline{v^{\prime} w^{\prime}}-\nu \frac{\partial \bar{V}}{\partial z}\right)-f \bar{U}, \\
& \frac{\partial \bar{\Theta}}{\partial t}=-\frac{\partial}{\partial z}\left(\overline{\theta^{\prime} w^{\prime}}-\chi \frac{\partial \bar{\Theta}}{\partial z}\right)-\frac{\partial \bar{R}}{\partial z}, \\
& \underbrace{\frac{\partial e^{2}}{\partial t}}_{\mathrm{S}}=-\underbrace{\frac{\partial}{\partial z} \overline{e^{2} w^{\prime}}}_{\mathrm{T}}-\underbrace{2 \bar{\epsilon}}_{\mathrm{D}}-\underbrace{2\left(\overline{u^{\prime} w^{\prime}} \frac{\partial \bar{U}}{\partial z}+\overline{v^{\prime} w^{\prime}} \frac{\partial \bar{V}}{\partial z}\right)}_{\mathrm{M}} \\
& +\frac{2 g \beta \overline{\theta^{\prime} w^{\prime}}}{\mathbf{P}}, \\
& \underbrace{\frac{\partial \overline{\theta^{\prime 2}}}{\partial t}}_{S^{\prime}}=-\underbrace{\frac{\partial \frac{\partial}{\partial z} \overline{\theta^{\prime 2} w^{\prime}}}{2}}_{\mathrm{T}^{\prime}}-\underbrace{2 \overline{\epsilon_{\theta}}}_{\mathrm{D}^{\prime}}-\underbrace{2 \overline{\theta^{\prime} w^{\prime}} \frac{\partial \bar{\theta}}{\partial z}}_{\mathbf{M}^{\prime}}
\end{aligned}
$$

with

$$
\begin{aligned}
\left\{\overline{u^{\prime} w^{\prime}}, \overline{v^{\prime} w^{\prime}}\right\} & =-K_{M}\left\{\frac{\partial \bar{U}}{\partial z}, \frac{\partial \bar{V}}{\partial z}\right\}, \\
\overline{\theta^{\prime} w^{\prime}} & =-K_{H} \frac{\partial \bar{\theta}}{\partial z}+g \beta \frac{l\left(1-C_{6}\right)}{C_{5}} \frac{\overline{\theta^{\prime 2}}}{e}, \\
\left\{\overline{e^{2} w^{\prime}}, \overline{\theta^{\prime 2} w^{\prime}}\right\} & =-C_{7} l e\left\{\frac{5}{3} \frac{\partial e^{2}}{\partial z}, \frac{\partial \overline{\theta^{\prime 2}}}{\partial z}\right\}, \\
\left\{\bar{\epsilon}, \bar{\epsilon}_{\theta}\right\} & =\frac{e}{l}\left\{C_{1} e^{2}, C_{2} \overline{\theta^{\prime 2}}\right\} .
\end{aligned}
$$

Here $t$ represents time, $\bar{U}, \bar{V}$ the horizontal components of the mean velocity field along east and north, and $z$ the upward vertical; $\bar{\theta}$ is the mean temperature; $\overline{u^{\prime} w^{\prime}}, \overline{v^{\prime} w^{\prime}}$ and $\overline{\theta^{\prime} w^{\prime}}$ respectively designate the components of the turbulent shear stress (divided by specific mass $\rho_{0}$ ) and heat flux (divided by the product of specific mass and specific heat $\left.C_{p}\right) ; \bar{R}$ is the radiative heat flux which penetrates to depth $z ; \nu$ and $\chi$ are respectively the kinematic viscosity and the thermal molecular diffusivity; $f$ is the Coriolis parameter; $e^{2}$ and $\overline{\theta^{\prime 2}}$ are the turbulent kinetic energy (divided by $\rho_{0} / 2: e^{2} \equiv \overline{u^{\prime 2}}+\overline{v^{\prime 2}}$ $\left.+\overline{w^{\prime 2}}\right)$, or TKE, and the temperature variance, whereas $2 \bar{\epsilon}$ and $2 \epsilon_{\theta}$ are the dissipation rate of $e^{2}$ and the destruction rate of $\overline{\theta^{\prime 2}}$, respectively; $g$ is the gravity constant and $\beta$ the coefficient thermal ex- pansion of sea water; $l$ is an integral length scale parameterized after Blackadar's (1962) suggestion; and $C_{1}, C_{2}, C_{5}, C_{6}$ and $C_{7}$ are numerical constants. $K_{M}$ and $K_{H}$ are turbulent exchange coefficients which are known algebraic functions of $l, e^{2}, \overline{\theta^{\prime 2}}$, their vertical gradients and those of $\bar{U}, \bar{V}$ and $\bar{\theta}$ (see the Appendix). Initial values for $\bar{U}, \bar{V}$ and $\bar{\theta}$ are given or observed values, while those for $e_{2}$ and $\bar{\theta}^{\prime 2}$ can be generated by the model. Upper boundary conditions for the heat and momentum equations are the surface heat flux and the surface wind stress, respectively. The turbulent kinetic energy flux from the atmosphere, associated with waves breaking, is parameterized as a boundary condition for $e^{2}$ in terms of friction velocity $u_{*}$. The surface flux of $\overline{\theta^{\prime 2}}$ is always set to zero. At some depth $(z=-D)$, such that the atmospheric effects have no influence, the value of $\bar{\theta}$ is given and $\bar{U}$ and $\bar{V}$ are nil; all turbulent moments are zero at this depth.

\section{b. Numerical implementation}

The five nonlinear parabolic-type partial differential equations (1)-(5) have been integrated in time using an implicit trapezoidal scheme free of stability constraint on the time step (Klein, 1980a,b). The spatial differentiations have been carried out with a finite-element method. These discretizations lead to solve at each time step a matricial equation of the form

$$
A(\mathbf{X}) \mathbf{X}=\mathbf{b},
$$

where $\mathbf{b}$ is a known vector, $\mathbf{X}$ a vector describing the unknowns $\left(\bar{U}, \bar{V}, \bar{\theta}, e^{2}, \bar{\theta}^{\prime 2}\right)$ and $\mathbf{A}(\mathbf{X})$ a matrix depending on $\mathbf{X}$. The solution adopted to solve this nonlinear problem involves splitting $A(X)$ into a regular part $A_{1}(X)$ and a residual part $A_{2}(\mathbf{X})$, i.e.,

$A_{1}(X) X=C(X)$, with $C(X)=b-A_{2}(X) X$.

The nonlinear problem (11) is then converted into a fixed point problem the solution of which is found by using the so-called generalized successive approximations method (Crouzeix, 1974). In most of the simulations, the grid spacing $\Delta z$ is set at $1 \mathrm{~m}$ and time step $\Delta t$ at $1 \mathrm{~h}$ : a computation time of $150 \mathrm{~s}$ is required for a 10 days simulation of $60 \mathrm{~m}$ deep marine layer, using an IBM 370-3033 computer.

\section{c. The physics of the model}

Eqs. (1)-(3) demonstrate that the evolution of the marine upper layers is governed by vertical turbulent fluxes, the proper evolution of which is linked, after (4) -(9), to the variations of the other turbulent fluxes, and the levels and scales of TKE and temperature variance. In this SSOM, only two differential equations are retained for the description of turbulent transfer processes, those for $e_{2}$ and $\overline{\theta^{\prime 2}}$ in which transport effects and storage rates are explicity taken 
into account. But buoyancy and inhomogeneity effects for all second-order moments are mostly taken into account in (6) and in (7) after which a countergradient heat flux can be obtained.

The terms in the TKE and temperature variance budgets must be examined to understand the roles of the main turbulent mechanisms. In Eq. (4), for TKE, we can identify the shear production term $M$ which represents the transformation of the mean motion kinetic energy (or MKE) into TKE, and the buoyancy production or destruction term $\mathrm{P}$ which describes the transformation of potential energy (or PE) into TKE. D is the rate of dissipation of TKE into internal energy (or IE) through the viscous forces. $T$ is a diffusion term, corresponding to the divergence of the vertical turbulent flux of TKE, and the tendency term $S$ represents the local rate of storage of TKE. In Eq. (5) for $\theta^{\prime 2}$, we identify the production term $\mathbf{M}^{\prime}$, representing the interaction between the mean temperature field and turbulence. $D^{\prime}$ is the rate of destruction of temperature variance under the effect of molecular conductivity, $T^{\prime}$ the divergence of the vertical turbulent flux of $\theta^{\prime 2}$, and $\mathrm{S}^{\prime}$ the local storage rate of $\overline{\theta^{\prime 2}}$.

The basic difference between the present SSOM and the mixed-layer model of Mellor and Durbin (1975, hereafter referred to as MD) lies in the fact that we explicitly take into account storage and transport of $e^{2}$ and $\overline{\theta^{\prime 2}}$. In MD they are neglected, so that TKE production is immediately and locally dissipated; the role of turbulence is then restricted to a spatial transfer of the mean energies and a local exchange from KE into IE and PE (Klein, 1980b). Herein, the effects of rapid and localized productions and destructions of $e^{2}$ and $\overline{\theta^{\prime 2}}$ will be properly damped.

In particular, TKE will be transported by Eq. (8) from the high-level toward the low-level zones, thus leading to increased thermocline erosion. It must be noted in that respect that if (7) allows a countergradient gravitational heat flux, (8) does not take into account the gravitational contribution to third-order moments (see the Appendix). This contribution has been shown (Zeman, 1975) to lead in strongly convective situations to a countergradient TKE flux from the gravitationally unstable production zone toward the stably stratified region, thus contributing to much more important TKE transport, and therefore to increased erosion.

Kundu's (1980) investigation makes use of the Gibson and Launder (1976) model, which is rather similar to the present one, with the exception of differences in the modeling of the dissipation rate and the temperature variance. Another probably significant difference lies in the treatment of the vertical turbulent fluxes, upon which the dominant effect of the vertical velocity component is more adequately expressed here (see the Appendix).

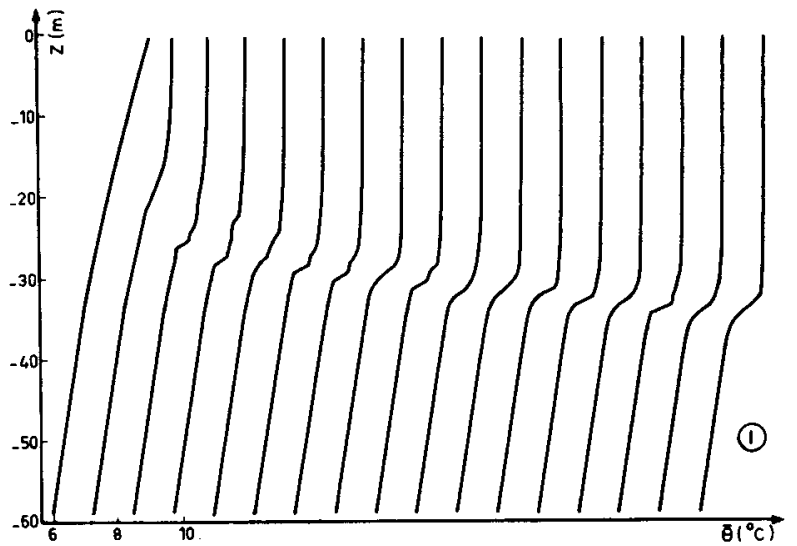

FIG. 1. Temperature profile evolution due to an impulsive wind and a zero surface heat flux (simulation I). Profiles are plotted every $6 \mathrm{~h}$, each being displaced from the preceding one by $1.25^{\circ} \mathrm{C}$.

Warn-Varnas and Piacsek (1979) use a more complex model which explicitly takes into account gravitational effects in the parameterization of the thirdorder TKE transport terms. The specific influence of these gravitational effects, however, is difficult to appreciate since they have not yet looked at cases of surface heating or cooling.

\section{A study of the effects of specific dynamical at- mospheric forcings}

The simulations to be described in this section bring into play different purely dynamical forcings in order to examine their particular effects on the mean and turbulent structures of the marine upper layers. Thus, the radiative and turbulent surface heat fluxes are set to zero all times. Note that each simulation is referred to by a roman number in the paper and figures.

\section{a. Response to an impulsive wind stress with zero surface TKE flux (simulation I)}

The sea is initially at rest and the initial temperature profile is stable (Fig. 1). A surface wind stress of $2 \times 10^{-4} \mathrm{~m}^{2} \mathrm{~s}^{-2}$, corresponding to a $11 \mathrm{~m} \mathrm{~s}^{-1}$ west wind, is applied after $t=0$. The surface flux of TKE due to wave breaking is assumed to be zero.

After the mean temperature profile evolution (Fig. 1), the mixed layer thickens rapidly during the first hours and more slowly later. Comparison of these results with those obtained (Klein, 1980b) using the Mellor and Durbin's (1975) model, reveals the more important mixed-layer deepening predicted by the SSOM (the difference is $-3 \mathrm{~m}$ after a 4-day simulation for reasons to be discussed below). The distribution of current modulus (Fig. 2) is nonuniform and unsteady within the mixed layer, and presents periodically a strong shear near the thermocline. The dimensionless TKE profiles (Fig. 3) be- 


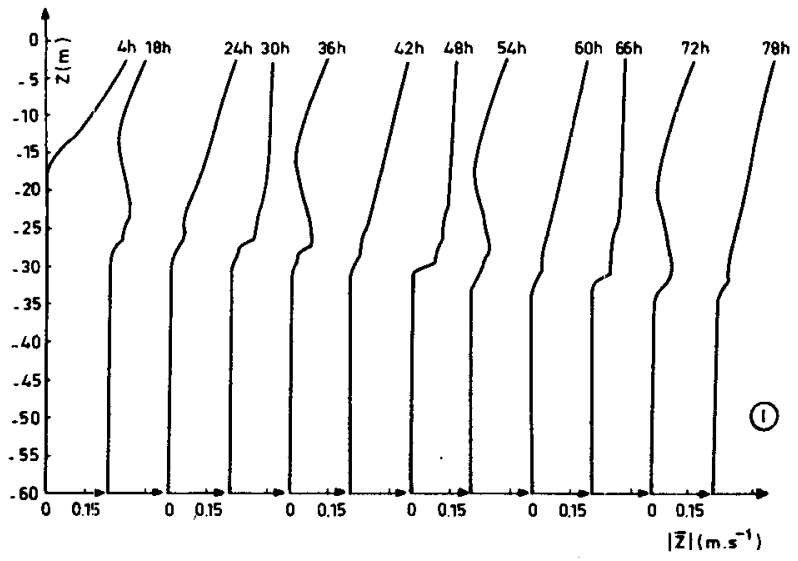

FIG. 2. Current modulus profile evolution for simulation 1 .

come linear and steady after a transitory period, while the temperature variance, nil near the surface, is a maximum near the base of the mixed layer, due to the simultaneous presence of a strong mean temperature gradient and an appreciable turbulent intensity. The distribution with depth of the TKE budget [Eq. (4)] has been examined in dimensionless variables, its terms being divided by $u_{*}{ }^{3} / l_{0}$ and $z$ by $l_{0}$. After a transitory period corresponding to the rapid initial deepening, a steady situation is reached in that appropriate similarity representation (Figs. $4 a$ and $4 b$ ). A linear-logarithmic representation of the same budget is given in dimensional form in Fig. 5 for a better display of the smaller terms. The minimum in the buoyancy term $P$ identifies the base of the mixed layer since the turbulent heat flux divergence is positive above, corresponding to mixedlayer cooling, and negative below, corresponding to

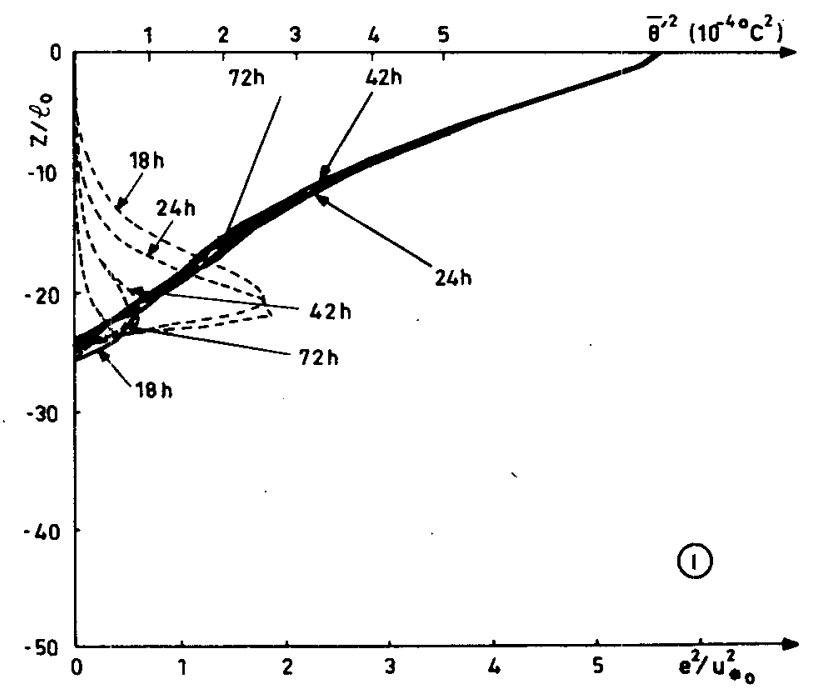

FrG. 3. Dimensionless profiles of TKE (solid line) and temperature variance (dashed line) at different times for simulation I.

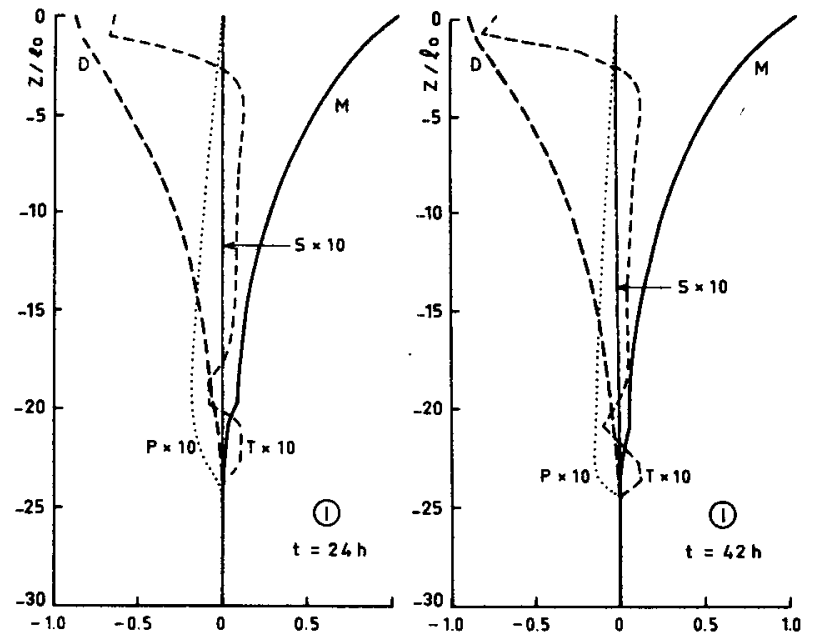

FIG. 4. Dimensionless simulation I TKE budget at $t=24 \mathrm{~h}$ (a) and $42 \mathrm{~h}$ (b) showing, $M$ mechanical production, D dissipation, $\mathrm{P}$ buoyant production, $\mathrm{T}$ turbulent transport, and $\mathrm{S}$ storage.

the heating due to thermocline erosion. In the mixedlayer, shear production $M$ and dissipation $D$ are most important and practically in equilibrium, which indicates a dominant effect of mechanical processes, as found by Warn-Varnas and Piacsek (1979) and Kundu (1980). At the second-order, the transport T, negative in the first meters, becomes positive within the mixed layer: examination of the TKE flux itself (Fig. 6) reveals an overall transport from the surface layers toward the thermocline. The gravitational production $P$ is also of second order within the mixed layer, whereas storage $S$, is quite small everywhere. In the thermocline region, all terms except $S$ are of

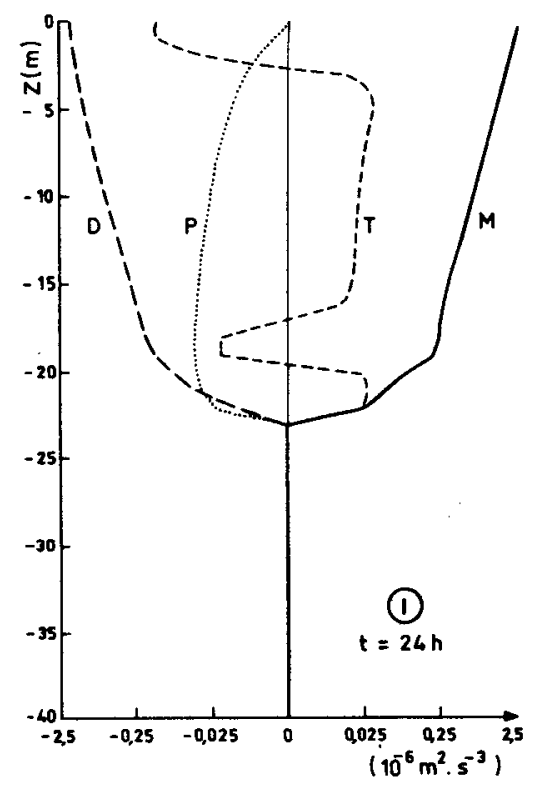

FIG. 5. Dimensionless TKE budget at $t=24 \mathrm{~h}$ (simulation I) Symbols as in Fig. 4. 


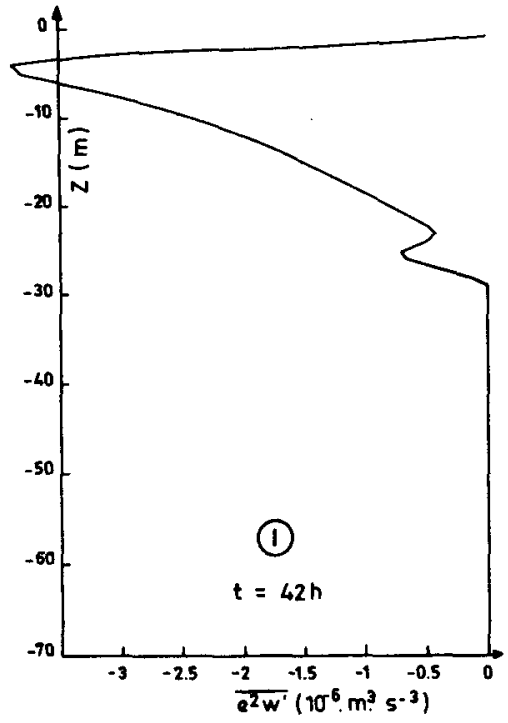

FIG. 6. Distribution of the vertical turbulent flux of TKE at $t=42 \mathrm{~h}$ (simulation I).

the same order of magnitude, as found by Garwood (1977) and Warn-Varnas and Piacsek (1979) but not by Kundu (1980). More precisely, the profile of $M$ presents a secondary bump at the mixed-layer base (see Figs. 4 and 5), associated with a local increase of the TKE flux (Fig. 6). The SSOM thus predicts a transport of TKE from the bottom of the mixed layer, where local current shear causes an increased production, towards the thermocline for which transport $T$ is a significant TKE source (Fig. 5) used for the stable layer erosion. These results put into evidence the important role of turbulent TKE diffusion in the deepening mechanism, thus explaining the more important deepening obtained with the SSOM than with the MD model. This has been confirmed by making $C_{7}=0$ (i.e., $T=0$ ) in the SSOM: the final mixedlayer depth was then practically the same as given by MD.

\section{b. Response to an impulsive wind stress with non- zero surface TKE flux (simulation II)}

Another simulation of the same typical situation has been carried out, but with a nonzero value for the surface TKE flux in order to explore the effects of wave breaking on mixed-layer deepening. From dimensional considerations, the flux has been parameterized by

$$
\left.\overline{e^{2} w^{\prime}}\right|_{z=0}=-m u_{*}^{3} \text {. }
$$

In this simulation we have chosen $m=10$, which is in accordance with the values recently reviewed by Gargett et al. (1979). The evolution of the mean temperature and current fields is quasi-identical with the one found in simulation $I$, which confirms the results found by Kundu (1980). Analysis of the di- mensionless TKE budget (Fig. 7) reveals that most of the TKE diffusing from the surface is dissipated within the first few meters. The most important effect is that $M$ is less important near the surface than in (I), because of the greater uniformity of the current field due to the increased mixing. A simulation carried out with $m=20$ has confirmed these results. Thus, the effects of the surface waves breaking do not appear to be important in a windy situation with regard to the mean thermal and dynamical structure evolution and can be ignored in various models. More precisely, these effects seem to be limited to the first meters close to the surface wherein a reduced mechanical production and an increased dissipation equilibrate the turbulent diffusion of TKE from the surface: the increased turbulent mixing in this region should certainly be taken into account in certain applications (e.g., biological models). Again, after these results the TKE transported within the thermocline seems to be mainly a consequence of the current shear at the mixed-layer base.

\section{c. Response to a sudden reduction of the wind stress (simulations III and IV)}

When the wind stops after a given duration $(t=35$ $h$ here) the results indicate, as in Klein (1980b), no further significant deepening of the mixed layer, a reduction of the temperature gradient within the thermocline, and significant residual inertial current oscillations. It is interesting to examine the spatial and temporal evolution of the TKE budget under such circumstances. As shown on Fig. 8, in the first hours after $t=35 \mathrm{~h}, \mathrm{M}$ presents a maximum in the

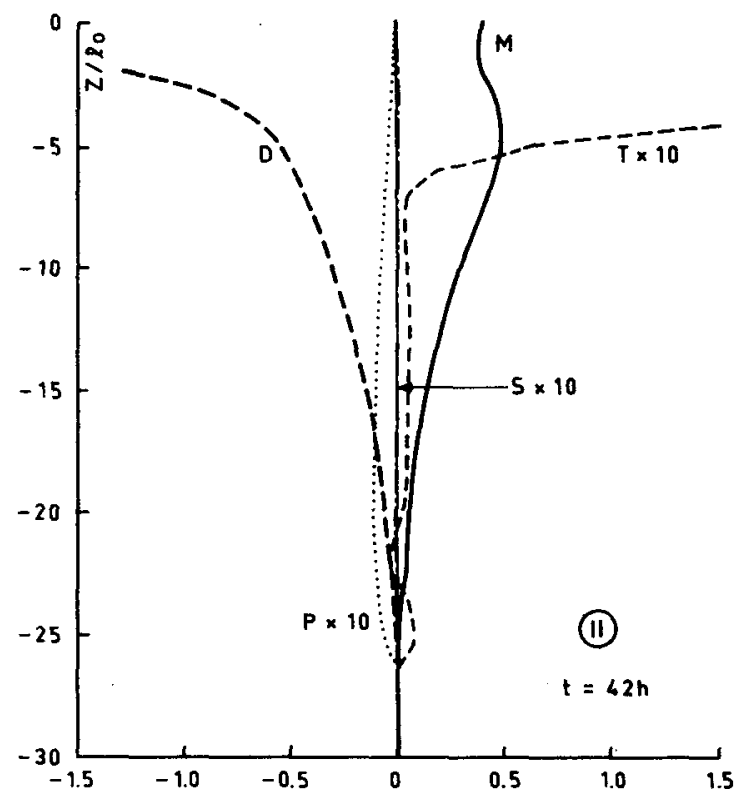

FIG. 7. Dimensionless TKE budget at $t=42 \mathrm{~h}$ (simulation II) Symbols as in Fig. 4. 


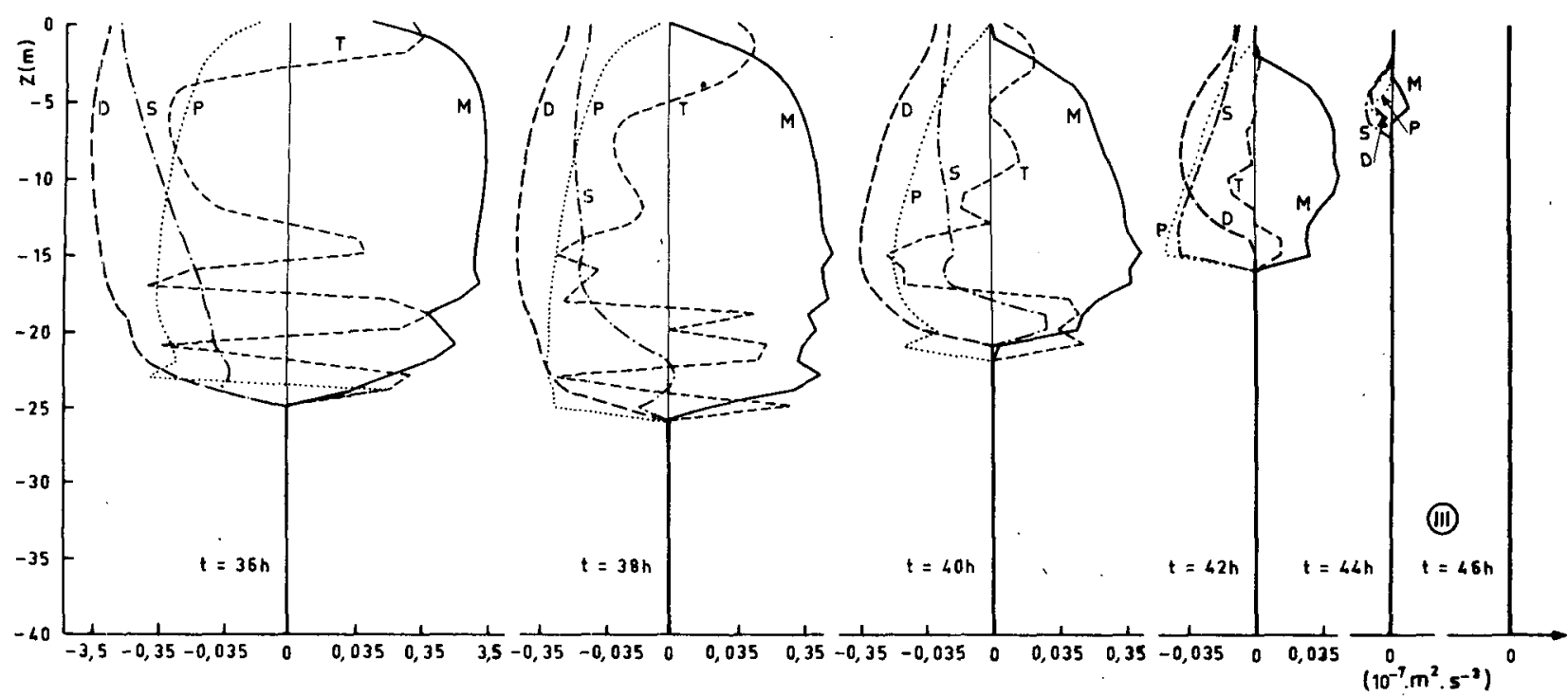

FIG. 8. Dimensionless TKE budget at different times after the wind stops (simulation III). Symbols as in Fig. 4.

middle of the mixed layer, approximately equilibrated by $D$. Quite rapidly, the total rate of destruction of TKE under the combined effects of $D$ and $P$ exceeds at the lowest levels the local rate of shear production $\mathbf{M}$. Thus, in spite of transport $T$ and storage $S$ effects, the turbulent mechanisms die out starting from the bottom, so that the thickness of the turbulent layer is reduced to zero in a matter of $10 \mathrm{~h}$. In that case, the stabilizing buoyancy effects are so strong as to reduce the level of turbulence to such an extent that current shear at the mixedlayer base is no longer effective as at TKE source.

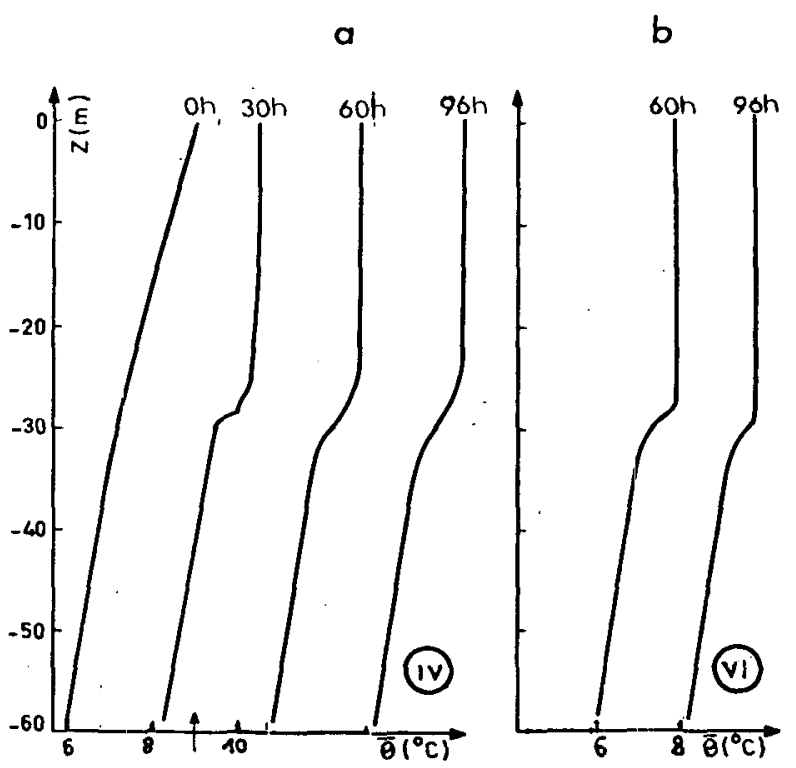

FIG. 9. Temperature profile evolutions when the wind stress is suddenly reduced at $t=35 \mathrm{~h}$ (a) without (simulation IV) and (b) with (simulation VI) surface cooling.
Another simulation (IV) has been carried out with a residual $2 \times 10^{-5} \mathrm{~m}^{2} \mathrm{~s}^{-2}$ surface wind stress after $t=35 \mathrm{~h}$. The resulting temperature (Fig. 9a) and current (Fig. 10a) evolutions are quite similar to those obtained above, but a significant difference appears for the turbulence field: first diminishing after the wind stress reduction, it reaches a new state of equilibrium (Fig. 11a) with a limited spatial extension and a greatly reduced level. As in the preceding case, the residual inertial oscillations appear as practically quasi-permanent, a behavior which has been observed at sea (Gonella, 1971). Again, this is a consequence of the stabilizing effects at thermocline level which reduce to zero the turbulent friction due to local shear; the MKE associated with the oscillating mean current field is no longer transformed into TKE and finally dissipated into heat so

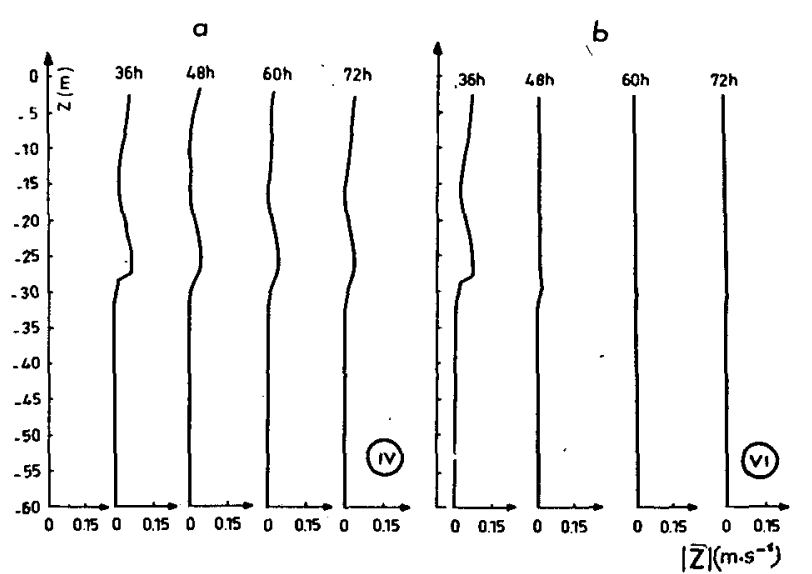

Fig. 10. Current modulus profile evolutions for simulations IV and VI. 


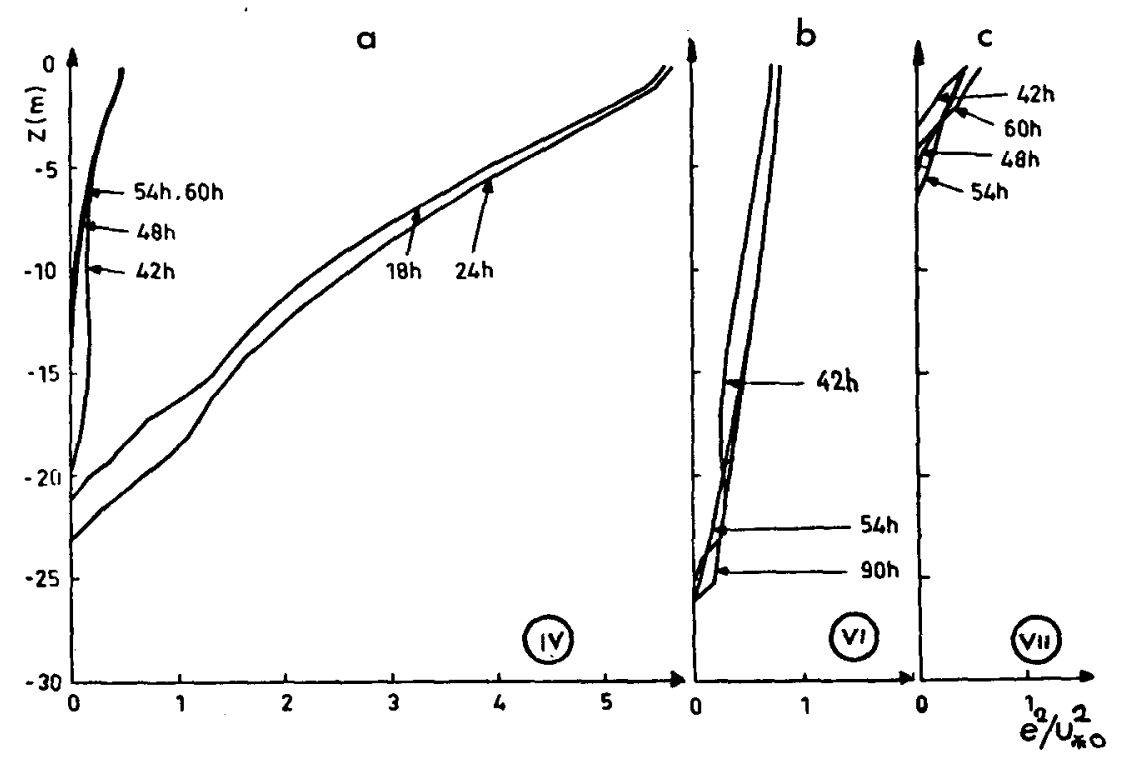

FIG. 11. TKE profiles at different times when the wind stress is suddenly reduced at $t=35 \mathrm{~h}$ (a) without surface cooling (simulation IV), (b) with surface cooling (simulation VI), or (c) with surface heating (simulation VII).

that the upper layers behave more or less as free slabs.

\section{d. Influence of the time variability of the wind stress}

The unsteady character of the mean and turbulent structures of marine upper layers subjected to particular atmospheric forcings leads to the study of the long-term influence of the variability of the latter. Such an investigation already has been made in Klein

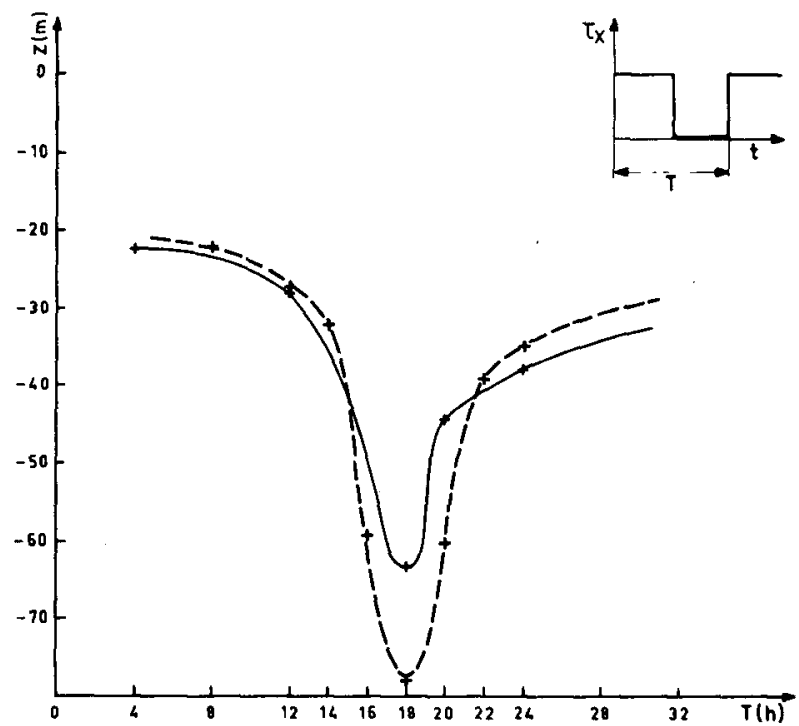

FIG. 12. Final mixed layer characteristic depth, after $96 \mathrm{~h}$ simulations with SSOM (solid line) and MD (dashed line), as a function of the wind sequence period $\mathrm{T}$. (1980b) with the MD, in particular for the influence of the wind action periodicity on mixed-layer deepening. This influence was again investigated with the SSOM, through several simulations wherein the surface heat, TKE and temperature variance fluxes are kept to zero while the surface wind stress, of amplitude $2 \times 10^{-4} \mathrm{~m}^{2} \mathrm{~s}^{-2}$ is periodic with a characteristic time period between 4 and $24 \mathrm{~h}$. The final mixed-layer depths predicted by SSOM and MD are given in Fig. 12 as a function of the wind sequence

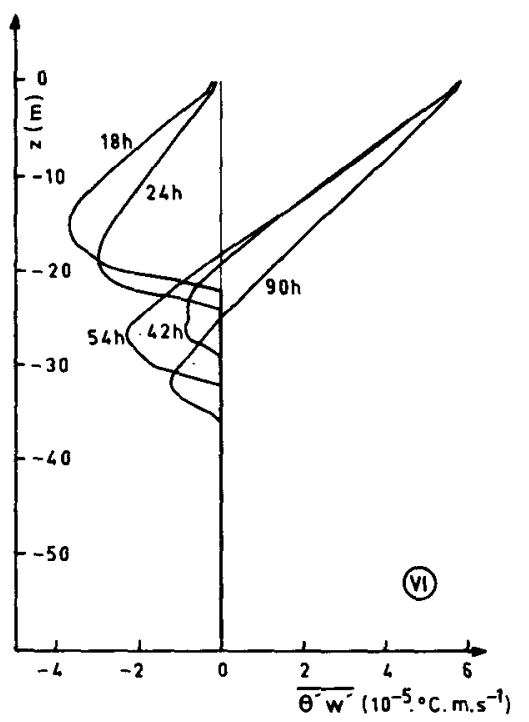

FIG. 13. Turbulent heat flux profiles for an impulsive wind, and a strong positive surface heat flux applied after $t=35 \mathrm{~h}$ (simulation V). 


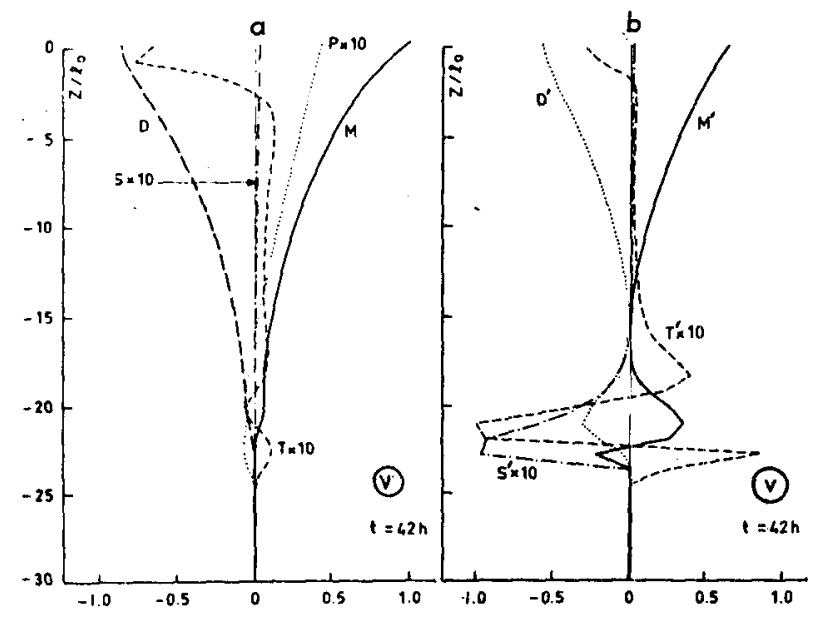

FIG. 14. Dimensionless TKE budget (a) and temperature variance budget (b), at $t=42 \mathrm{~h}$ for simulation V. Symbols: (a) as in Fig. 4 ; (b) $M^{\prime}$, gradient production; $D^{\prime}$, dissipation: $T^{\prime}$, transport; $S^{\prime}$, storage.

periodicity: a very important deepening is obtained for periods close to the Coriolis. However, this deepening is less important for SSOM than for MD, while for smaller and longer periods the final depth is slightly greater with SSOM than with MD. One can conjecture that, for periods close to the Coriolis, the capability of SSOM to describe TKE storage and release reduces the amplitude of variations in the level of turbulent transfers and then damps the resonance mechanism found with $\mathrm{MD}$. For longer and shorter periods, the increased final deepening is again a consequence of the inclusion of the TKE diffusion mechanism in SSOM.

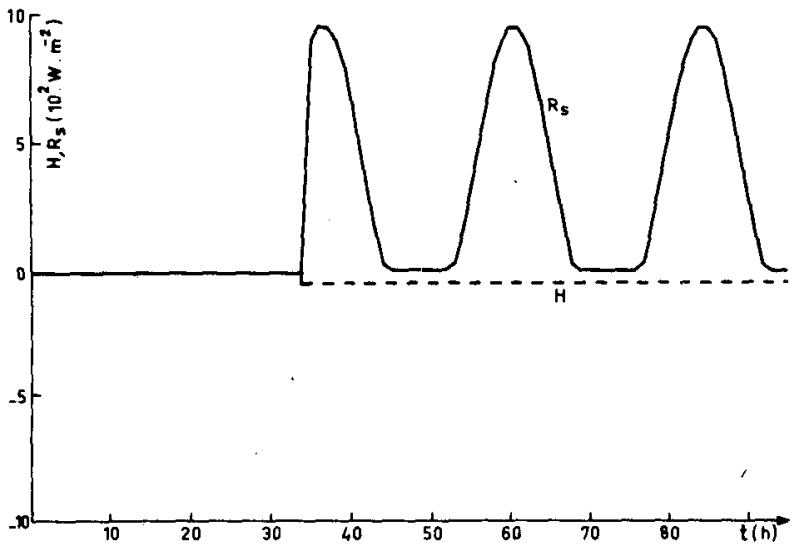

FIG. 16. Evolution of the surface solar radiative flux (solid line) and of the surface budget of infrared radiative and latent and sensible turbulent heat fluxes (dashed line) (simulation VII).

\section{A study of the effects of simultaneous thermal and dynamical atmospheric forcings}

As far as we know, no investigation of the effects of thermal atmospheric forcings on the structure of turbulence in the marine upper layers has still been published (Mellor and Durbin's discussion is limited to their effect on the mean structure). It is certainly important to explore to what extent those forcings affect the level and spatial extension of turbulence, and consequently the different turbulent mechanisms which control the mixed layer and thermocline behavior. For this aim, several simulations similar to the preceding for the imposed wind stress, but with nonzero surface heat fluxes, have been carried out (TKE and $\overline{\theta^{\prime 2}}$ surface fluxes are kept zero). In each

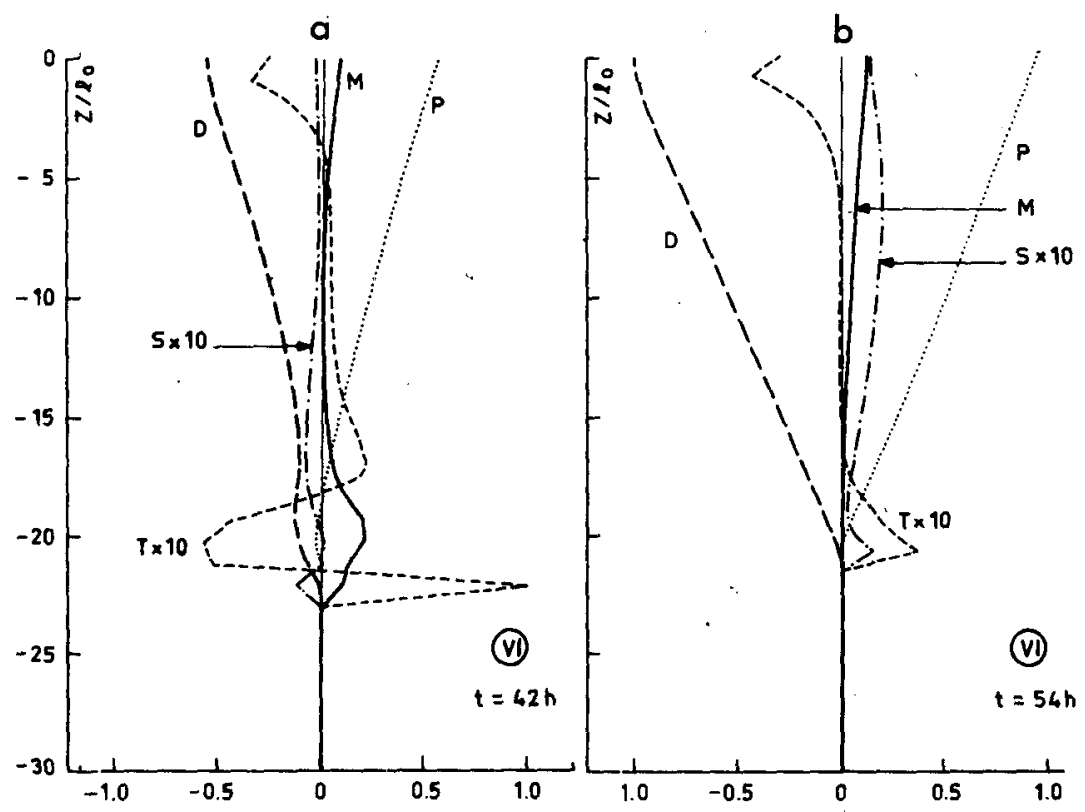

FIG. 15. Dimensionless TKE budgets at $t=42 \mathrm{~h}$ and $t=54 \mathrm{~h}$ for simulation VI. 


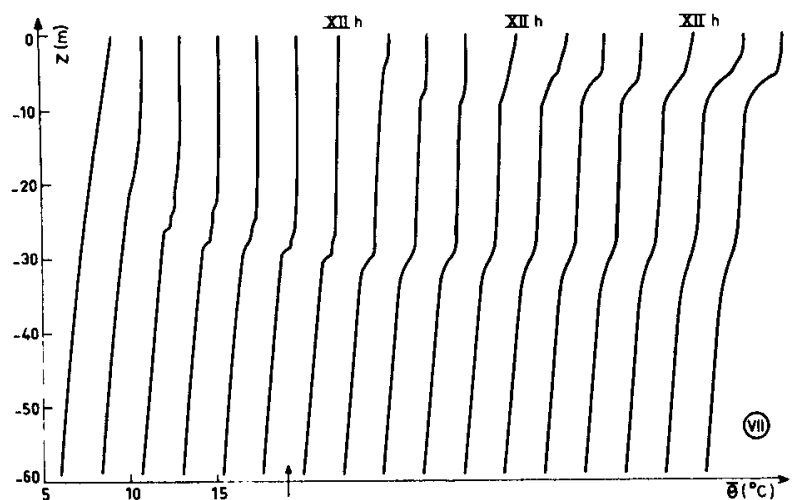

FIG. 17. Temperature profile evolution in response to a negative surface heat flux and a reduced wind stress after $t=35 \mathrm{~h}$ for turbid waters (simulation VII). Profiles are plotted every $6 \mathrm{~h}$ with meridian times noted, each one being displaced from preceding one by $2.4^{\circ} \mathrm{C}$.

case, a mixed layer is first generated using the same initial and boundary conditions as above, then different surface heat fluxes are applied after $t=35 \mathrm{~h}$.

\section{a. Response to a positive surface heat flux under a strong wind}

Simulation $V$ concerns a permanent surface wind stress of $2 \times 10^{-4} \mathrm{~m}^{2} \mathrm{~s}^{-2}$ and a positive surface turbulent heat flux (cooling) of $250 \mathrm{~W} \mathrm{~m}^{-2}$, the radiative flux being supposed zero. A more important (by $4 \mathrm{~m}$ after four days) deepening is predicted than in the corresponding zero heat flux case (I). The turbulent heat flux, although positive in the upper part of the mixed layer, reaches a negative minimum in its lower part (Fig. 13) corresponding to a penetrative convection mechanism and a permanent erosion of the stable zone. The TKE repartitions are found to be quasi-identical to those of case I, and their dimensionless budgets rather similar (cf. Fig. 14a with Fig. 4b). The small positive contribution of $P$ to TKE production in the upper part of the mixed layer in the present case is apparently compensated by a slight decrease in $\mathbf{M}$ in this area, associated with a better current homogeneization, and therefore a slightly greater MKE transport and current shear at the mixed-layer base. In case $V$ as in case $I$, the final deepening mechanism seems to be mainly controlled by TKE diffusion from this level of dynamical production toward the stable zone. This situation is entirely different from the convective atmospheric boundary-layer case, wherein $P$ is the dominant production term and the inversion erosion is controlled by a global upward TKE transport necessitating the inclusion of gravitational effects in the third-order moments parameterization (see Zeman, 1975; Andre et al., 1978; Deardorff, 1980).

The temperature variance budget (Fig. 14b) betrays production regions in the upper part and at the bottom of the mixed layer, from which $\overline{\theta^{\prime 2}}$ is exported toward its middle and the thermocline. The existence there of a negative production zone, corresponding to a countergradient heat flux, can be noticed.

\section{b. Response to a positive surface heat flux with a reduced wind}

Simulation VI corresponds to the same surface cooling as above, $250 \mathrm{~W} \mathrm{~m}^{-2}$, but to a wind stress reduced to $2 \times 10^{-5} \mathrm{~m}^{2} \mathrm{~s}^{-2}$ after $t=35 \mathrm{~h}$, as in simulation IV. Surface cooling is found to affect significantly both the thermal structure (as evident in Fig. $9 \mathrm{~b}$, a well-defined thermocline is maintained) and the residual current field (the amplitude of which rapidly decreases to a quite weak value, as shown by Fig. 10b). The corresponding TKE budget (Fig. 15) reveals that gravitational production $P$ in approximate balance with $D$, is at present the main source term within the mixed layer. During the first hours after the cooling outset, a significant level of shear production $M$ subsists at the base of the mixed layer, maintaining penetrative convection (Fig. 15a). At a later stage (Fig. 15b), the current reduction is such that $\mathrm{M}$ disappears and $\mathrm{P}$ can only maintain a non-penetrative convection process, in spite of a certain level of transport $\mathrm{T}$ at the thermocline level. The situation now parallels the convective atmospheric boundary-layer case, and the present SSOM, where, as in Yamada and Mellor (1975), gravitational contributions to the third-order moments are ignored since $C_{8}$ is taken to be zero (see the Appendix), is likely to underestimate the transport and entrainment mechanisms which are found important with other models (Zeman, 1975; Zeman and Lumley, 1976; Andre et al., 1976; 1978). In any case, comparison of simulations VI and IV shows that surface cooling allows the maintenance of a significant TKE level within the whole mixed layer (cf. Fig. 11b and 11a), which is responsible for the rapid damping of residual current oscillations, shown in Fig. 10.

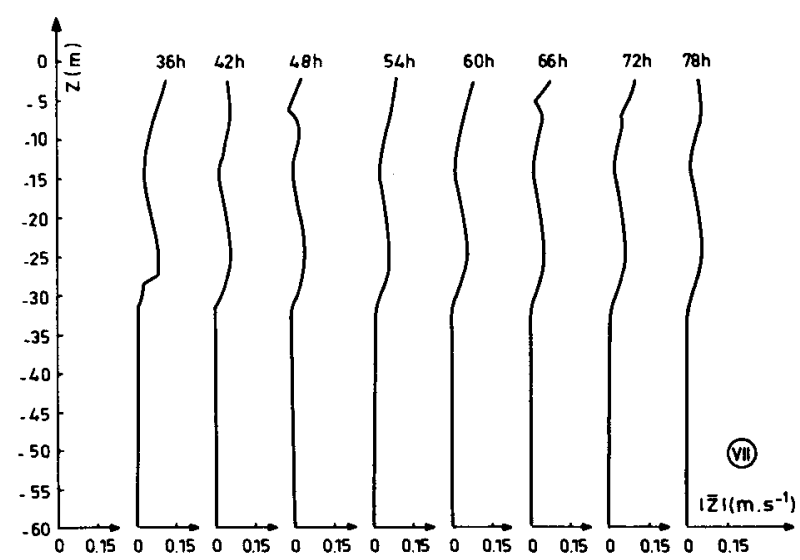

FIG. 18. Current modulus variation (simulation VII). 


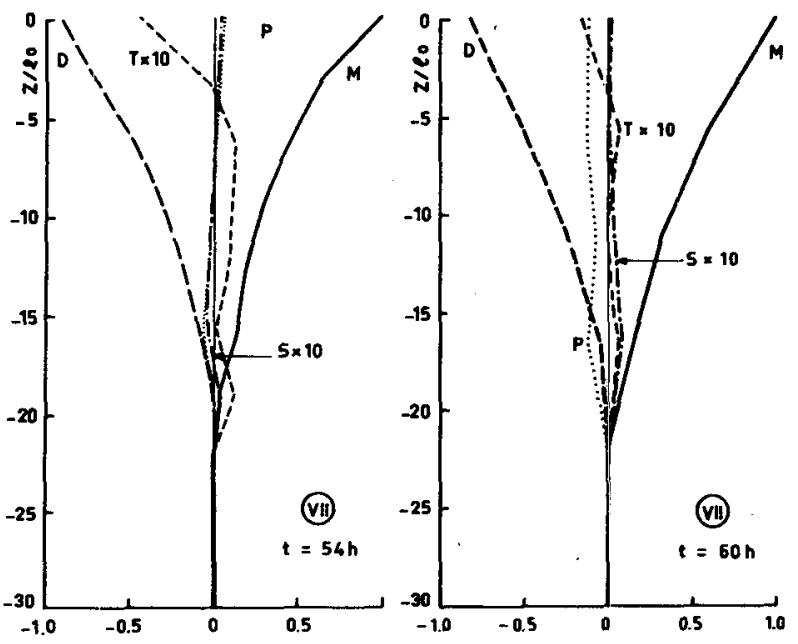

FIG. 19. Dimensionless TKE budget at $t=54 \mathrm{~h}$ (nighttime) and at $t=60 \mathrm{~h}$ (daytime) for simulation VII. Symbols as in Fig. 4.

\section{c. Response to a negative surface heat flux (heating)}

Simulation VII has been carried out, using after $t=35 \mathrm{~h}$ a reduced surface wind stress of $2 \times 10^{-5}$ $\mathrm{m}^{2} \mathrm{~s}^{-2}$ and a surface heat flux combining (Fig. 16) an evoluting solar radiative input $R_{S}$ and a steady $40 \mathrm{~W} \mathrm{~m}^{-2}$ turbulent heat loss $\mathrm{H}$ corresponding to the sum of longwave radiative, and sensible and latent turbulent heat fluxes at the surface. The penetration of solar radiation is described with the classical formula

$$
\bar{R}(z)=R_{S}\left[m_{s} e^{\eta_{1} z}+\left(1-m_{s}\right) e^{\eta_{2 z} z}\right],
$$

where $m_{s}=0.78, \eta_{1}=0.66, \eta_{2}=0.125$, corresponding to rather turbid sea water (Paulson and Simpson, 1977) have been adopted.

As Fig: 17 shows, the main thermocline progressively lessens, while a new thermocline develops near the surface, with a well-marked diurnal varia-
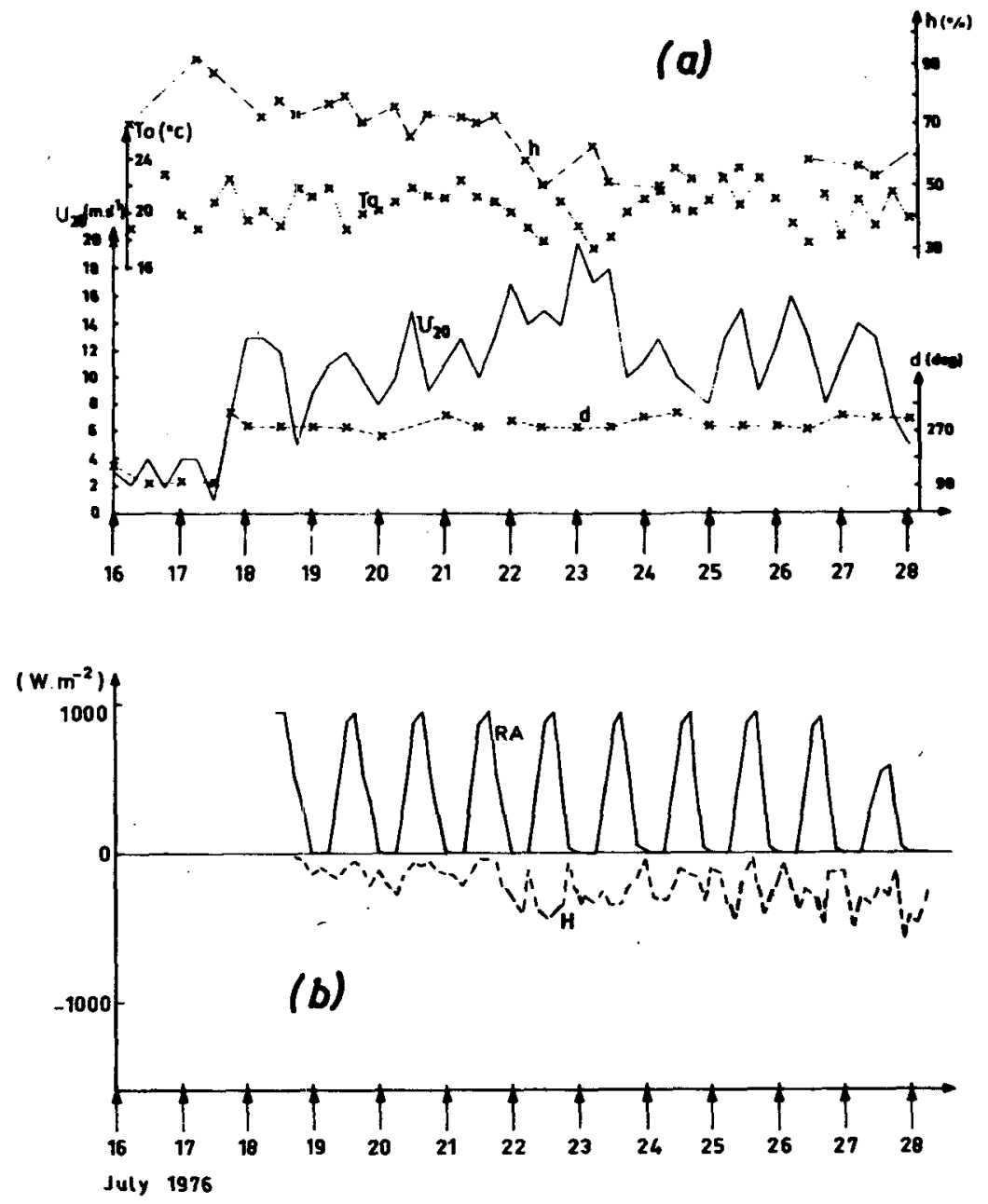

FIG. 20. (a) Temporal variation of wind speed and direction ( $U_{20}$ and $d$ ), dry bulb temperature $\left(T_{a}\right)$, and relative humidity $(h)$, during COFRASOV II. (b) evolution of surface heat fluxes during COFRASOV $I I$. 
tion (a stable region appears at the end of the day, and a well-mixed layer at the end of the night). Like in case IV, the current field evolution (Fig. 18) displays a strong residual oscillation at the lowest levels, but well-marked additional variations now appear within the first few $(\sim 7)$ meters. As a consequence of the stabilizing solar input, the final spatial extension of turbulence is smaller than in IV (cf. Figs. 11c and 11a). The dimensionless TKE budget (Fig. 19) naturally betrays a certain diurnal variability, with a particularly significant gravitational TKE destruction $(\mathrm{P}<0)$ during the day.

\section{Comparisons of the model results with experi- mental data}

Because of obvious difficulties, practically no direct data exist on the turbulent mechanisms in the upper marine layers, with the noticeable exception of some determinations of dissipation rates (see e.g., Gargett et al., 1979; Oakey and Elliott, 1980). The SSOM predictions of repartitions and orders of magnitude for $\mathrm{D}$ do not contradict the limited available data. For instance, the model gives a total dissipation rate of $2.6 \times 10^{-2} \mathrm{~W} \mathrm{~m}^{-2}$ for a $11 \mathrm{~m} \mathrm{~s}^{-1}$ wind velocity for which Oakey and Elliott (1980) report values scattered around $10^{-2} \mathrm{~W} \mathrm{~m}^{-2}$.

Data sets concerning the thermal structure evolution as a function of surface forcings are more easily available. Field and laboratory experiments will be used.

\section{a. Simulation of the COFRASOV II mixed-layer and thermocline data}

The observations made by the Laboratoire d'Océanographie Physique from the laboratory buoy BORHA II during the COFRASOV II expedition are described in Klein (1980b): they include hourly micrometeorological measurements (Fig. 20a) and temperaturedepth records every $2 \mathrm{~h}$, leading to the time-depth isothermal contours shown in Fig. 21a. It is demonstrated in Klein (1980b) that the observed thermal structure evolution can be correctly simulated with the MD, but only if the unusually high exchange coefficient $C_{10}=1.7 \times 10^{-3}$ is adopted. A new simulation has been made with SSOM, using classical methods for estimating solar and infrared radiative fluxes, and the usual value $C_{10}=1.5 \times 10^{-3}$ for the exchange coefficient; the resulting surface fluxes are shown in Fig. 20b. Solar penetration was parameterized after (13), with $m_{s}=0.4, \eta_{1}=0.2, \eta_{2}$ $=0.025$ after Paulson and Simpson (1977) for very clear waters, and the surface flux of TKE was neglected in view of the results of simulation II.

The calculated thermal structure (Fig. 2lb) is not modulated by internal waves, these being ignored by the model, and the time-depth isothermal contours under the thermocline are on the average almost

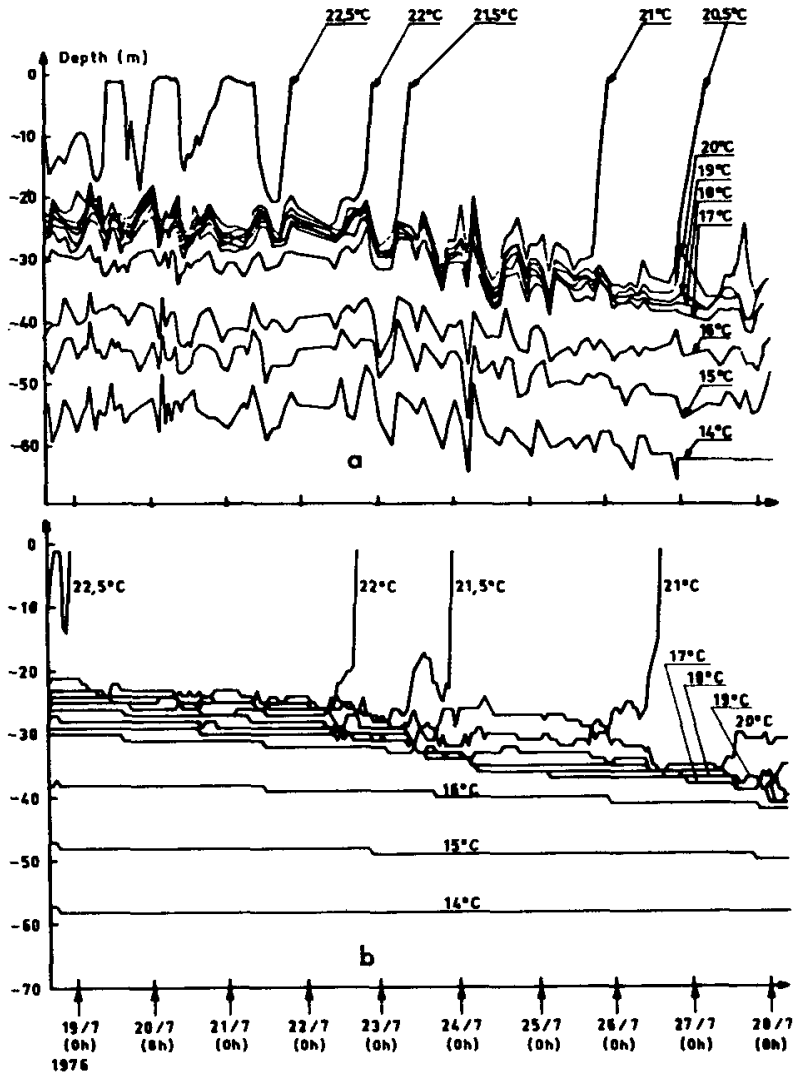

FIG. 21. Observed (a) and computed (b) time-depth isothermal contours during COFRASOV II.

level, since advection phenomena also are ignored. Furthermore, the temperature gradient within the thermocline is significantly smaller after 23 July than that shown by measurements. Nevertheless, the thermal structure computed with SSOM shows a rather satisfactory overall agreement with the observations, both with respect to surface temperature (Fig. 22a) and the deepening of the thermocline (Fig. 22b). It must be noted that this agreement is obtained independently of any coefficient adjustment in either the model or the surface fluxes estimation. In view of the sensitivity analysis performed in Klein (1980b), this demonstrates again that the inclusion of tendency and diffusion effects in the SSOM closure represents a significant improvement with respect to the physics of the MD.

\section{b. Comparison of entrainment rates with the results of Kato and Phillips}

The experiments of Kato and Phillips (1969) provide a classical basis of comparison for the rate of entrainment of a stably stratified fluid by a well-mixed turbulent layer. The nondimensional entrainment rates,

$$
E=\frac{d h}{d t} \times \frac{1}{u^{*}},
$$




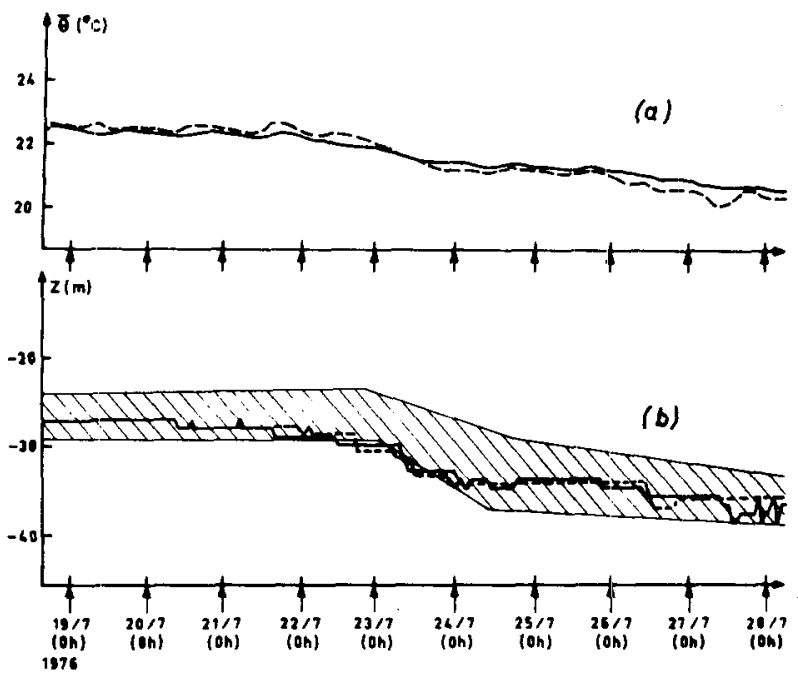

FIG. 22. Simulation of the COFRASOV II case: (a) Observed (dashed) and computed (solid) sea surface temperature; (b) computed time-depth isothermal contour $\left(18.5^{\circ} \mathrm{C}\right)$ with SSOM (solid) and MD (dashed). The hatched area shows the region where the rapid variations of the measured time-depth isothermal contours 18 and $19^{\circ} \mathrm{C}$ are located.

where $h$ is the depth of penetration of the turbulent zone, and the corresponding bulk Richardson numbers,

$$
\mathrm{Ri}_{0}=g\left(\frac{\partial \rho}{\partial z}\right)_{0} \frac{h^{2}}{2 \rho_{0} u_{*}^{2}},
$$

have been determined after the SSOM in different situations. Results from the first few hours of a simulated marine mixed-layer deepening event are shown as triangles in Fig. 23. Direct simulations were also performed of the laboratory situation where the water mass, initially at rest with a constant density gradient, is subjected to a given surface stress after $t=0$. The cases $N=\left[g(\partial \rho / \partial z)_{0} / \rho_{0}\right]^{1 / 2}=1.38$ and $2.82 \mathrm{~s}^{-1}$, and $u_{*}{ }^{2}=0.995$ and $2.75 \times 10^{-4} \mathrm{~m}^{2} \mathrm{~s}^{-2}$, led to the results shown as a dashed line. The latter are quite close to the predictions of Warn-Varnas and Piacsek (1979), and in rather good agreement with the average experimental data, while the MD results also shown on Fig. 23 are significantly below. Once more, and as noted by the above authors, this illustrates the necessity of taking into account the TKE diffusion mechanism for obtaining adequate entrainment rates.

\section{Conclusions and discussion}

A one-dimensional time-dependent simplified second-order model, similar to that of Mellor and Yamada's (1974) level 3, has been implernented and used to study the dynamical and thermal turbulent and average structures of the marine mixed layer and thermocline in a variety of situations. It must be noted that the truly implicit numerical scheme allowing small $(1 \mathrm{~m})$ space and large $(\geqslant 1 \mathrm{~h})$ time steps constitutes a significant improvement over most existing models. The results concern in particular the turbulent mechanisms which contribute to fix the dynamical and thermal turbulence levels, and the resulting distributions of the latter.

In most of the simulations, the TKE budget shows an equilibrium between the mechanical production and the dissipation mechanisms. As a consequence, neglecting gravitational effects in some closure parameterizations or considering anisotropy as a small parameter (as Mellor and Yamada, 1974, have done), has probably no critical consequence.

A problem, however, arises when gravitational production becomes a dominant term in the TKE budget, as was found in the weak wind-strong cooling case (VI) and can be expected for some deep winter thermoclines. As mentioned above, the inclusion of the gravitational influence in the TKE transport parameterization would then be advisable. This could be done as in the sophisticated atmospheric boundary-layer models, or maybe more simply by giving $C_{8}$ a nonzero value [of order 20 (see Klein, 1980a)] in the present simplified model. It must be noted, however, that such convective marine situations as VI are not common occurrences. During windless nights, the surface heat loss is generally below $40 \mathrm{~W} \mathrm{~m}^{-2}$ (Warsh, 1973) so that the resulting convective erosion is probably limited; strong evaporative coolings up to 400 or $500 \mathrm{~W} \mathrm{~m}^{-2}$ are in general associated with the passage of an atmospheric front, leading to high winds and strong mechanical effects.

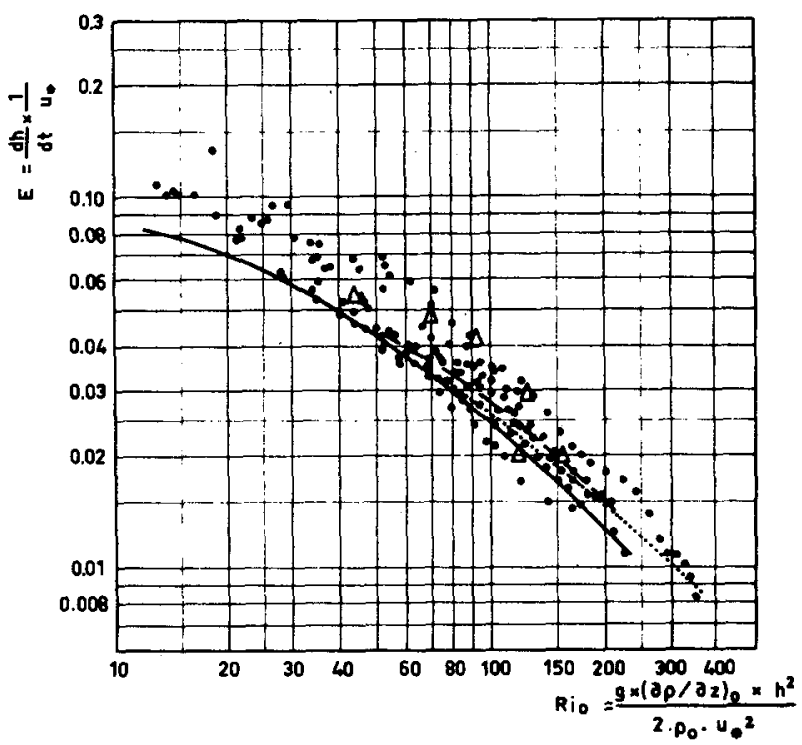

FiG. 23. Comparison between entrainment rates predicted by the present SSOM (dashed line and triangles), Mellor and Durbin (1975) (solid line), Warn-Varnas and Piacsek (1979) (dotted line), and the experimental data of Kato and Phillips (dots). 
The simulations of windy situations demonstrate the importance of the turbulent diffusion of TKE. Though not very important within the mixed layer, this mechanism plays a decisive role in the thermocline deepening by allowing a significant transport of TKE from the base of the mixed layer to within the thermocline, where it is used for the erosion of the stable layers. This explains the more important deepening obtained with the SSOM than with MD, which neglects TKE transport. Similar conclusions have been reached by Garwood (1977) and WarnVarnas and Piacsek (1979), but not by Kundu (1980) as discussed by Deardorff (1980).

TKE input due to surface wave breaking does not have an overall significant effect. As observed by Kundu (1980), its influence is limited to the first meters near the surface where the turbulence intensity is increased and the mechanical and dissipation terms have a compensatory effect in the TKE budget. This result confirms that, as observed by Garwood and Camp (1977), Price et al. (1978) and Gargett et al. (1979), when the depth is great enough, mixed-layer deepening is not being driven directly from the surface but by the shear instability at the mixed-layer base. It should be noted, however, that only TKE generation due to wave breaking has been considered here - possible interactions between the orbital motion and turbulence, have not been taken into account.

The spatial and temporal decrease and dying out of turbulence has been investigated after a sudden wind-speed reduction with a zero surface heat flux. This leads to a reduction, starting from the mixedlayer base as described in Gargett et al. (1979), of the extension of the turbulent zone, which is limited afterward to the first meters close to the surface as a function of the new wind speed. During this process, the storage term becomes a non-negligible TKE source.

The level and spatial extension of turbulence appear to be very significantly affected by the surface heat flux. The effect of surface cooling is to maintain or intensify turbulence in the mixed layer, leading to an increased turbulent diffusion and hence to a more important current shear at the mixed-layer base. If the mixed-layer current resulting from the surface wind stress is sufficiently large, thermocline erosion is clearly accentuated. On the contrary, the effect of surface heating is to reduce the turbulence level and extension. A transitory thermocline is observed, the depth and shape of which vary depending on solar radiation penetration and surface heat flux changes.

Finally, it has been demonstrated that the structure of the upper marine layers not only depends on the nature and amplitude of the air-sea energy transfers but also is strongly affected by the characteristic time scales of the marine fluid medium (as, for example, the fundamental Coriolis period). The investigations with SSOM of the long-term influence of the unsteady character of the atmospheric forcings has confirmed the results already obtained with MD, and shown the damping effect of TKE and temperature variance diffusion and storage. In addition, the comparison of SSOM results with field data demonstrates its ability to reproduce a real marine situation without any coefficient adjustment.

The present investigation has illustrated the influence of particular turbulent mechanisms on the mean thermal and dynamical marine structures. Moreover, it has also revealed the important sensitivity of the vertical TKE distribution to atmospheric forcings. Though not always significant from the thermal and dynamical points of view, this sensitivity must be taken into account when considering biological variables, the variations of which are, most of the time, significant inside the mixed layer itself.

Acknowledgments. This study was carried out in part under Electricité de France Institut de Mécanique Statistique de la Turbulence Contracts $16336,16175,16079$. We extend our gratitude to M. Joseph Jacquet, Head of the "Environnement Aquatique et Atmosphérique" Département Electricité de France. We also warmly thank John Lumley and Otto Zeman for their interest and advice, and the researchers of the Laboratoire d'Océanographie Physique du Muséum National d'Histoire Naturelle for having provided us with their data from the COFRASOV II expedition.

\section{APPENDIX}

\section{Derivation of the Simplified Second-Order Model}

\section{Turbulence closures}

The evolution of the turbulent fluxes apparent in Eqs. (1)-(3) depends on second-order moment equations (see, e.g., Coantic, 1978), which are closed as follows (Klein, 1980a):

- The dissipation terms are parameterized, as in Mellor and Yamada (1974) and Andre et al. (1976), using the typical length scale $l$ proposed by Black$\operatorname{adar}(1962)$, i.e.,

$$
\begin{aligned}
& \frac{1}{l}=\frac{1}{\kappa|z|}+\frac{1}{l_{0}}, \quad \kappa=0.35 \\
& l_{0}=0.10 \int_{-\infty}^{0} e|z| d z / \int_{-\infty}^{0} e d z .
\end{aligned}
$$

Using an independent equation for $\bar{\epsilon}$, as in Zeman and Lumley (1976) or Gibson and Launder (1976), should allow in principle a better description of buoyancy effects, in particular in stable situations, but at the cost of including new poorly known constants. 
- The pressure terms are parameterized after Launder (1975), as in Andre et al. (1978). Buoyancy effects are included, while they are not in Mellor and Yamada (1974). Neglecting these effects leads to the appearance of a spurious surface thermocline, as observed and explained by Wyngaard and Cote (1974), in the atmospheric case.

- The third-order terms are parameterized after Hanjalic and Launder (1972) and Donaldson (1973). This does not take into account the buoyancy effects which, as discussed in Section 2c, should have been included in certain cases. Following a suggestion by Zeman, a term $C_{8} g^{2} \beta^{2} l^{3} e^{-1} \overline{\partial \theta^{\prime 2}} / \partial z$ was proposed as the gravitational contribution to $\overline{e^{2} w^{\prime}}$ in Klein (1980a), but not used in the numerical simulations since much too little was known about the constant $C_{8}$.

$$
\begin{aligned}
K_{M}= & A_{1} \overline{w^{\prime 2}}+A_{2}, \\
K_{H}= & \frac{l}{C_{5} e} \overline{w^{\prime 2}}, \\
A= & 1+g \beta \frac{l^{2}\left(1-C_{4}\right)}{C_{3} C_{5} e^{2}} \frac{\partial \bar{\Theta}}{\partial z}, \\
A_{1}= & \frac{l\left(1-C_{4}\right)}{C_{3} e}\left[1-g \beta \frac{l^{2}\left(1-C_{6}\right)}{C_{5}^{2} e^{2}} \frac{\partial \bar{\theta}}{\partial z}\right] A^{-1}, \\
A_{2}= & \frac{l\left(1-C_{4}\right)}{C_{3} e} g^{2} \beta^{2} \frac{l^{2}}{C_{5}^{2} e^{2}}\left(1-C_{6}\right)^{2} \overline{\theta^{\prime 2}} A^{-1}, \\
\overline{w^{\prime 2}}= & \frac{e^{2}}{3}+2 \frac{l}{C_{3} e} \frac{\partial}{\partial z}\left(\frac{2}{9} C_{7} l e \frac{\partial e^{2}}{\partial z}\right)+\frac{2}{3} \frac{l\left(1-C_{4}\right)}{C_{3} e}\left[-A_{2}\left|\frac{\partial \bar{Z}}{\partial z}\right|^{2}+2 g^{2} \beta^{2} \frac{l\left(1-C_{6}\right)}{C_{5} e} \overline{\theta^{\prime 2}}\right]
\end{aligned} .
$$

The values of the physical constants in the equations are

$$
\begin{gathered}
f=10^{-4} \mathrm{~s}^{-1}, \quad \beta=1.73 \times 10^{-4}{ }^{\circ} \mathrm{C}^{-1}, \quad C_{p}=4200 \mathrm{~J} \mathrm{~kg}^{-1}{ }^{\circ} \mathrm{C}^{-1}, \quad g=9.81 \mathrm{~m} \mathrm{~s}^{-2}, \\
\nu=0.134 \times 10^{-5} \mathrm{~m}^{2} \mathrm{~s}^{-1}, \quad \chi=0.134 \times 10^{-6} \mathrm{~m}^{2} \mathrm{~s}_{-}^{-1}, \quad \rho_{0}=10^{3} \mathrm{~kg} \mathrm{~m}^{-3} .
\end{gathered}
$$

\section{REFERENCES}

André, J. C., G. De Moor, P. Lacarrere and R. Du Vachat, 1976: Turbulence approximation for inhomogeneous flows. J. Atmos. Sci., 33, 476-491.

,,,--- G. Therry and R. Du Vachat, 1978: Modeling the 24-hour evolution of the mean and turbulent structures of the planetary boundary layer. J. Atmos. Sci., 35, 18611883.

Blackadar, A. K., 1962: The vertical distribution of wind and turbulent exchange in neutral atmosphere.J. Geophys. Res., 67, 3095-3102.

Coantic, M., 1978: An introduction to turbulence in geophysics and air-sea interactions. AGARDograph No. 232, 1-242.

Crouzeix, M., 1974: Étude d'une méthode de linéarisation. Résolution rumérique des équations de Stokes stationnaires. Application aux équations de Navier-Stokes stationnaires. Cah. No. 12, IRIA, Le Chesnay.
Deardorff, J. W., 1980: Comments on "A numerical investigation of mixed-layer dynamics." Reply by P. K. Kundu. J. Phys. Oceanogr., 10, 1695-1697.

Donaldson, C. du P., 1973: Construction of a dynamic model of atmospheric turbulence and the dispersal of atmospheric pollutants. Workshop in Micrometeorology, D. Haugen, Ed., Amer. Meteor. Soc., 313-392.

Gargett, A. E., T. B. Sanford and T. R. Osborn, 1979: Surface mixing layers in the Sargasso Sea. J. Phys. Oceanogr., 9, $1090-1111$.

Garwood, R. W., 1977: An ocean mixed layer model capable of simulating cyclic states. J. Phys. Oceanogr., 7, 456-468.

—, and N. T. Camp, 1977: Comments on "Climatological numerical models of the surface mixed layer of the ocean." J. Phys. Oceanogr., 7, 469-470.

Gibson, M. M., and B. E. Launder, 1976: On the calculation of horizontal turbulent free shear flow under gravitational influence. J. Heat Transfer, Trans. ASME, 98c, 81-87. 
Gonella, J., 1971: A local study of inertial oscillations in the upper layer of the ocean. Deep-Sea Res., 18, 779-788.

Hanjalic, K., and B. E. Launder, 1972: A Reynolds stress model of turbulence and its application to thin shear flows. J. Fluid Mech., 52, 609-638.

Jamart, B. M., D. F. Winter, K. Banse, G. C. Anderson and R. K. Lam, 1977: A theoretical study of phytoplankton growth and nutrient distribution in the Pacific Ocean off the northwestern U.S. coast. Deep-Sea Res., 24, 753-773.

Kato, H., and O. M. Phillips, 1969: On the penetration of a turbulent layer into a stratified fluid. J. Fluid Mech., 37, 643-665.

Klein, P., 1980a: Modélisation des mécanismes turbulents dans les couches marines superficielles (couche mélangée et thermocline). Doctoral thesis, Université d'Aix-Marseille II, 266 pp. [Bull. Dir. Et. Rech. E.D.F., A1].

- 1980b: A simulation of the effects of air-sea transfer variability on the structure of marine upper layers. $J$. Phys. Oceanogr., 10, 1824-1841.

Kundu, P. K., 1980: A numerical investigation of mixed layer dynamics. J. Phys. Oceanogr., 10, 220-236.

Launder, B. E., 1975: On the effects of a gravitational field on the turbulent transport of heat and momentum. J. Fluid Mech., 67, 569-581.

Lumley, J. L., and B. Khajeh-Nouri, 1974: Computational modeling of turbulent transport. Turbulence, Diffusion, and Environmental Pollution, Advances in Geophysics, Vol. 18A, Academic Press, 169-192.

Mellor, G. L., and T. Yamada, 1974: A hierarchy of turbulence closure models for planetary boundary layers. J. Atmos. Sci., 31, 1791-1806.

- and P. A. Durbin, 1975: The structure and dynamics of the ocean surface mixed layer. J. Phys. Oceanogr., 5, 718-728.

Nihoul, J. C. J., Ed., 1980: Marine Turbulence. Elsevier, Oceanography Series, No. 28, $378 \mathrm{pp}$.
Oakey, N. S., and J. A. Elliott, 1980: Dissipation in the mixed layer near Emerald Basin. Marine Turbulence, J. C. J. Nihoul, Ed., Elsevier, 123-133.

Paulson, C. A., and J. J. Simpson, 1977: Irradiance measurements in the upper ocean. J. Phys. Oceanogr., 7, 952-956.

Price, J. F., C. N. K. Mooers and J. C. Van Leer, 1978: Observation and simulation of storm-induced mixed-layer deepening. J. Phys. Oceanogr., 8, 582-599.

Rodi, W., 1979: Turbulence models for environmental problems. Lecture Series 1979-2, Von Karman Institute for Fluid Dynamics, $1-88$.

Warn-Varnas, A. C., and S. A. Piacsek, 1979: An investigation of the importance of the third-order correlations and choice of length scale in mixed layer modelling. Geophys. Astrophys. Fluid Dyn., 13, 225-243.

Warsh, K. L., 1973: Relation of sea-air interface energy fluxes to convective activity in the tropical Atlantic Ocean. J. Geophys. Res., 78, 504-510.

Woods, J. D., Ed., 1981: Turbulence in the Ocean. Springer Verlag.

Wyngaard, J. C., and O. R. Coté, 1974: The evolution of the convective planetary boundary layer. A higher-order closure model study. Bound.-Layer Meteor., 7, 289-308.

Yamada, T., and G. Mellor, 1975: A simulation of the Wangara atmospheric boundary layer data. J. Atmos. Sci., 32, 23092329.

Zeman, O., 1975: The dynamics of entrainment in the planetary boundary layer. A study in turbulence modeling and parameterization. Ph.D. thesis, Pennsylvania State University, $1-216$.

__, and J. L. Lumley, 1976: Modeling buoyancy-driven mixed layers. J. Atmos. Sci., 33, 1974-1988.

Zilitinkevich, S. S., D. V. Chalikov and Y. D. Resnyansky, 1979: Modelling the oceanic upper layer. Oceanol. Acta, 2, 219-240. 